\title{
Training Medical Students in Diet Assessment and Brief Counseling
}

\author{
Emily A Johnston (D) \\ Jeannette M Beasley ${ }^{2}$ \\ Melanie Jay $^{3}$ \\ 'Biomedical Education, California Health \\ Sciences University College of \\ Osteopathic Medicine, Clovis, CA, USA; \\ ${ }^{2}$ Department of Medicine, NYU Langone \\ Health, New York, NY, USA; \\ ${ }^{3}$ Department of Medicine and \\ Department of Population Health, NYU \\ Langone Health, New York, NY, USA
}

Correspondence: Emily A Johnston Biomedical Education Department, California Health Sciences University College of Osteopathic Medicine, 2500

Alluvial Avenue, Clovis, CA, 936II, USA

Tel +l 973-768-5888

Email eajohnst@gmail.com

\begin{abstract}
Poor dietary choices are a leading cause of chronic disease, but nutrition is rarely discussed in clinical practice. Nutrition is taught in less than a third of medical schools and physicians in practice empirically report low levels of comfort and self-efficacy in discussing nutrition with patients. A two-part presentation was created and shared with second-year medical students at a college of medicine. Students were given pre-work that included a brief (15 minutes) pre-recorded presentation and an e-resource entitled "Practical Nutrition for the Primary Care Provider" and then engaged in a live virtual session with a brief lecture and question and answer period (45 minutes). A survey was administered following the live presentation to evaluate the extent to which the presentation met the stated objectives and could impact participants' future practice. One-hundred and six students participated in the live lecture. Eighty-eight students $(83 \%)$ provided survey feedback. Over two-thirds of respondents indicated that the presentation completely met the objectives, $57 \%$ indicated that they would definitely talk to patients with chronic disease about nutrition, and $52 \%$ indicated they would incorporate diet assessment in visits with patients with chronic disease. Nutrition is integral to disease prevention and management. Many students provided comments on the importance of the topic and benefit of the information. Further research is necessary to determine the optimal time and place for nutrition education in medical training. This presentation and e-resource are evidence-based, brief, and provided tools for participants to access once in practice.
\end{abstract}

Keywords: nutrition, undergraduate medical education, diet assessment, virtual lesson

\section{Introduction}

Poor diet quality is a global problem and contributes to chronic disease morbidity and mortality. ${ }^{1}$ Data suggest that in the United States, less than $13 \%$ of physician visits overall, and less than $25 \%$ of visits by patients with a diagnosis of a chronic disease include any nutrition counseling. ${ }^{2,3}$ Nutrition is inadequately discussed in medical care due to several barriers, including lack of training of physicians. ${ }^{4,5}$ Consistent with evidence-based medicine, training future physicians to help patients improve their diet quality to reduce disease risk is imperative. This would enhance the quality of medical training and of medical care and increase discussions of prevention and lifestyle in medical office visits.

The Nutrition Academic Award ${ }^{6}$ provided funding to medical schools in the early 2000 s to increase their ability to offer nutrition within the medical school curriculum; however, many programs are no longer supported or have not been updated. Since then, there have been numerous publications calling for increasing nutrition education for future physicians, ${ }^{7-10}$ including a Science Advisory from the 
American Heart Association. ${ }^{11}$ Currently, there are no standards for integration of nutrition into medical training creating a gap in standardization of teaching and evaluation of these programs. Therefore, it is imperative to offer a variety of perspectives and interventions to aid faculty in increasing the availability of this training for future healthcare providers.

Evidence from published surveys suggests that medical trainees are interested in learning more about nutrition and physicians in practice recognize this as an area lacking in their training. ${ }^{12}$ This manuscript details the implementation of a brief training on diet assessment and counseling in clinical care for medical students.

\section{Materials and Methods}

The Interclerkship Intensive (ICI) is a required 3-day intensive formative didactic experience that occurs intermittently during clinical training to focus on important topics in clinical medicine not covered during the preclinical or clerkship training. Following discussion with the Interclerkship Intensive directors and staff, we prepared a nutrition educational intervention for a group of second year medical students at NYU Grossman School of Medicine. All authors and ICI stakeholders agreed upon objectives and contributed to the Faculty Guide (Supplementary Materials). Students were provided with pre-work and then engaged in a live virtual session facilitated by the first author (EAJ) with a brief lecture and question and answer period. We provided evidence-based information via a pre-recorded session (15 minutes) and live session (45 minutes) with resources to prepare for the training, as well as resources to access in the future to help guide patient care. The target audience was medical students who completed their preclinical coursework. These materials were designed to help address the gap in nutrition training in undergraduate medical education.

Previous work by our team of physicians and registered dietitians includes the development and evaluation of an e-book focused on nutrition for primary care providers. ${ }^{13}$ The authors created the presentation material and provided access to the previously published ebook (Practical Nutrition for the Primary Care Provider) as part of the recommended prework reading (available at https://www. eajnutrition.com/ebook). The presentation provided statistics on chronic disease and on the benefit of nutrition for the prevention and management of these conditions. Students were then encouraged to think of diet assessment through the framework of the 5A's, an evidence-based behavior change framework that has been used in smoking cessation and weight management counseling within medical care, ${ }^{14}$ and then to assess their own diets. The presentation ended with a discussion of how students perceived the diet assessment process and guidance on how health-care providers can use a diet assessment to guide brief counseling for patients on healthy dietary choices. By the end of the presentation, students would be able to:

1. Describe the benefits of performing a nutrition assessment in a medical office visit.

2. Recognize indications for performing a nutrition assessment in a medical office visit.

3. Discuss the evidence for lifestyle interventions with a focus on evidence-based dietary interventions.

4. Access a variety of diet assessment tools.

5. Provide brief evidence-based diet counseling in clinical practice.

Due to the COVID-19 pandemic, we conducted the presentation virtually in two parts. The first part, entitled, "Diet Assessment in Medical Care", was pre-recorded and presented as prework to students. The video was approximately 15 minutes long to allow for students to spend time practicing their own diet assessments using the presented, evidence-based tools. Data on students' diets was not collected. In the second part, EAJ presented "Brief Diet Counseling in Medical Care" in a live virtual format which consisted of a brief lecture ( 25 minutes) followed by an interactive question and answer session. The presentation (available upon request from corresponding author) can be presented as a single session or as two sessions.

Following the presentation, students were asked to complete an online questionnaire to provide feedback on the sessions (Supplementary materials) as part of the existing quality improvement process. No identifying information was collected or provided to the authors. No other resources were required for this intervention. The following day, students were evaluated on the entire ICI via Objective Structured Clinical Exam (OSCE; data not presented). The use of this data met the IRB criteria for quality improvement as we report on data that was collected for program evaluation and not research purposes; no informed consent was required.

\section{Results}

One hundred and six second-year medical students participated in this educational intervention. The entire presentation was completed in approximately one hour. Eighty-eight 
students (83\%) completed the end-of-class survey. Over two-thirds of respondents indicated that the presentation met all learning objectives; less than $6 \%$ of respondents stated that any objective was unmet (Figure 1). Thirtynine percent of respondents indicated they would talk to all patients about nutrition and $49 \%$ said they would try to. More than half (57\%) of respondents agreed that they would definitely talk to patients with chronic disease about nutrition and $42 \%$ said they would try to (Figure 2). Thirty-one percent of respondents reported they would incorporate diet assessment into practice with all patients and $47 \%$ said they would try to, while $52 \%$ of respondents agreed they would incorporate diet assessment in visits with patients with chronic disease and $43 \%$ said they would try to.

Overall, comments were positive, including:

Lots of good tips
This session presented useful information that I do think I will use in practice, namely specific ways to assess diet.

This workshop was engaging and provided helpful tips for approaching and discussing nutrition with patients.

Very useful and practical advice given. Helped with OSCE and in having us realize the importance of these topics in health care.

Other comments were constructive, including:

Should have been a small group if the intention was to be interactive.

Will consider nutrition but would realistically devote large amounts of time if working in a primary care setting.

Comments relating to the overall event were noted by the ICI staff, but not related directly to this presentation, including:

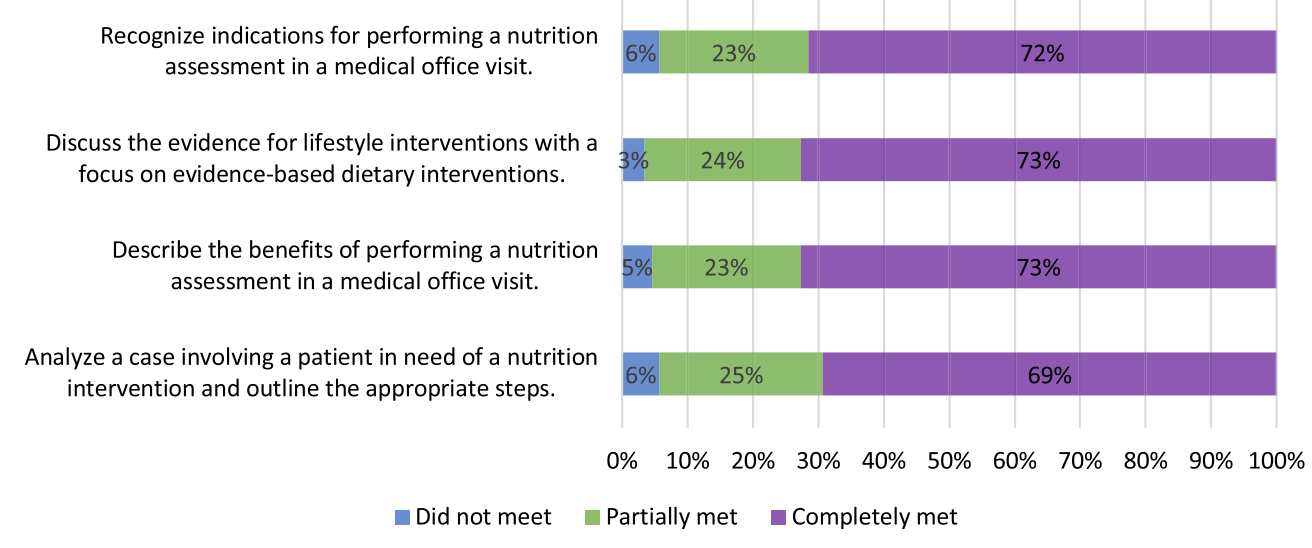

Figure I To what extent did this workshop achieve the goals and objectives or enhancing your ability to?

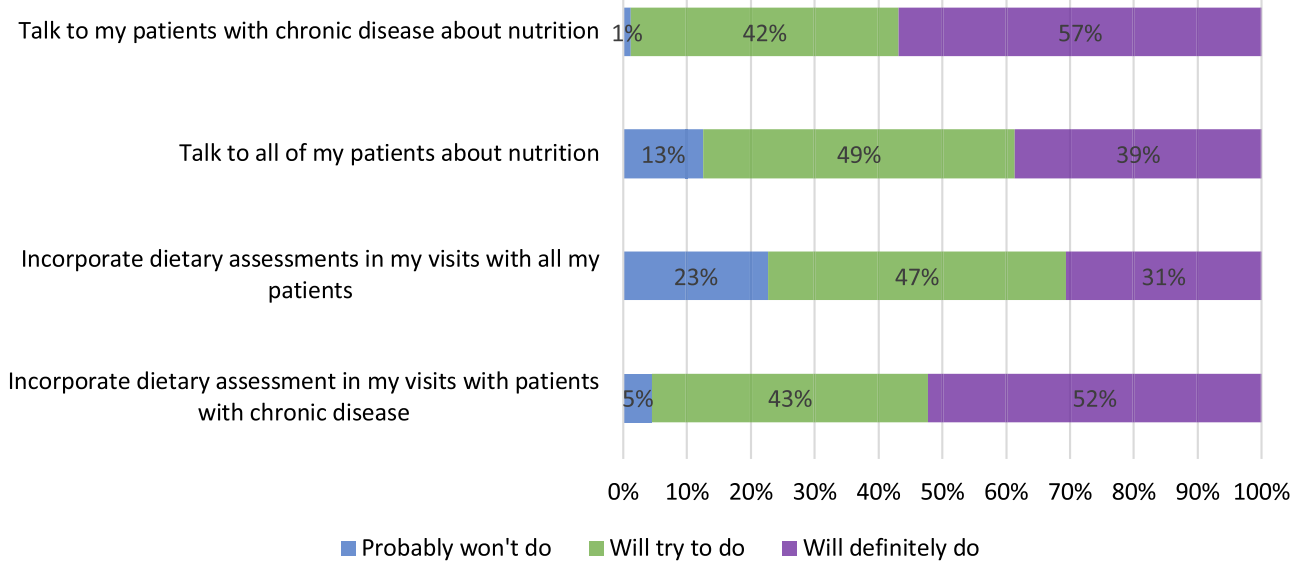

Figure 2 Please indicate the degree to which you plan, in your future practice, to do the following. 
I found that much of the information in these lectures could be consolidated in a fewer number of sessions. All sessions should be pre-recorded, there was no benefit to having a live-remote session about this.

I think we were not given all of the preparatory materials for this so it was hard to engage.

This session shouldn't have been at the end of a long and repetitive day - honestly it was hard to listen because I had been watching the screen and getting the same information all day.

\section{Discussion}

This educational intervention provided students with information on the role of nutrition in chronic disease risk and resources to improve skills in assessing diet quality and providing brief counseling to patients. It also provided the opportunity to practice using dietary assessment tools by assessing their own diets. This talk was attended by 106 second-year medical students, $83 \%$ of whom provided feedback. Overall, the feedback provided was positive and suggested that students learned valuable skills from the training. Some students suggested that the delivery be more interactive, including group work instead of lecturestyle training. Feedback regarding prework was that delivery of the pre-reading materials was not clear and the activities built into the live training could have been more engaging had the students been given earlier access and clearer instructions on the prework.

Practical Nutrition for the Primary Care Provider was selected as a pre-reading assignment for students in the current educational intervention as it provides recommendations for diet assessment tools, discusses evidence-based nutrition information, and provides information about using the 5 A's in practice for lifestyle change. There are few nutrition resources written specifically for medical students or physicians and those that exist are not of a practice-focused nature. Previous work from our group also includes creation and testing of a diet assessment tool $^{15}$ among family medicine residents (Johnston EA, Training Family Medicine Residents in Diet Assessment, under review), and integration of a dietary screener in a cardiovascular prevention practice. ${ }^{16}$ The focus of our collaborations is the improvement of nutrition training and resources for physicians and future physicians and this work allowed us to measure the impact of use of the ebook on a larger scale.
The content of this presentation was evidence-based and was developed collaboratively by physicians and registered dietitians. It included a basic introduction to diet assessment and provided students the opportunity to practice using a diet assessment tool and ask questions in an open forum. A chapter of the e-book is dedicated to the ways in which health-care providers from different disciplines can work together and the role of registered dietitians was highlighted in the presentation. Physicians are not expected to be nutrition experts; it is more relevant to their role to be conversant in basic nutrition topics and to refer to registered dietitians when further nutrition intervention is required. This information may also benefit health-care professional trainees from other disciplines.

Allowing students to work in groups to discuss the management of a patient presenting with a mock diet assessment would address some of the constructive comments on lecture time. An OSCE evaluating the entire day of presentations was required of students; data was not included here because it was not specific to this topic. OSCE's and other evaluations would add to the ability of the presenters to determine the perceived value of this talk. This presentation was a part of a larger event, some students reported that the prework was not easy to find or access, that there was some overlap with content of the other sessions, and that it would have been more beneficial to have small group breakout sessions. These comments were reviewed by the ICI directors and staff for future planning but were not directly related to the content of this session. These data reflect the feedback from one group of medical students, which may limit the generalizability of the findings. As such, we plan to replicate the training with other groups to establish generalizability.

\section{Conclusions}

Future directions include creation of a series of brief talks for students that involve interactive or small group sessions and can be spread through the preclinical and clinical years of undergraduate medical education. These could be guided by the ebook chapters, starting with students completing their own diet assessments (chapter 1), evaluating aggregate class data from the diet assessment tools, planning brief dietary interventions based on assessment data (chapter 2), recognizing barriers to behavior change and intervention strategies (chapter 3), utilizing other health-care team members and understanding appropriate referral strategies (chapter 4) and finally, focusing on weight loss and weight management in 
clinical care (chapter 5). Introducing students to this resource and to the links and practice papers referenced within will encourage the use of evidence-based resources in the future and introduce materials that are appropriate to share with patients as well. The ebook can also be a quick guide for educators without in-depth nutrition training. This training is available as a turn-key resource however, it is advisable to collaborate with a nutrition professional to implement this training. All tools and resources utilized in this intervention are made available upon request and we encourage educators to utilize them as appropriate. We must continue to publicize these interventions that are not resource-intensive (eg, there is not cost associated with any of the resources) to allow for seamless integration of nutrition education into medical training.

\section{Appendices}

Supplementary materials contain the FacultyGuide.docx and Evaluation_BLANK.doc. Presentation available upon request.

\section{Ethics and Consent Statements}

Data collected from students were part of the established quality improvement completed at NYU Grossman School of Medicine. No identifiable data was presented to the authors. We report on data that was collected for program evaluation and not research purposes and the authors only had access to aggregate results. Therefore, the use of such data did not quality as human subjects research as defined by the NYU Grossman School of Medicine IRB criteria and therefore did not require informed consent.

\section{Acknowledgments}

The authors would like to acknowledge Dr. Ruth Crowe for her support of this project.

\section{Author Contributions}

All authors contributed to analysis, drafting or revising the article, gave final approval of the version to be published, agreed to the submitted journal, and agreed to be accountable for all aspects of the work.

\section{Funding}

This project received no funding.

\section{Disclosure}

The authors report no conflicts of interest in this work.

\section{References}

1. GBD 2017 Diet Collaborators. Health effects of dietary risks in 195 countries, 1990-2017: a systematic analysis for the Global Burden of Disease Study 2017. Lancet. 2019;393(10184):1958-1972. doi:10.1016/S0140-6736(19)30041-8

2. Increase the proportion of health care visits by adults with obesity that include counseling on weight loss, nutrition, or physical activity NWS-05 - Healthy People 2030 | health.gov. Available from: https:// health.gov/healthypeople/objectives-and-data/browse-objectives/over weight-and-obesity/increase-proportion-health-care-visits-adultsobesity-include-counseling-weight-loss-nutrition-or-physical-activitynws-05. Accessed November 19, 2020.

3. US Department of Health and Human Services. Office of Health Promotion and Disease Prevention. Healthy People 2020: nutrition and Weight Status Objectives. Healthy People 2020; 2018. Available from: https://www.healthypeople.gov/2020/topicsobjectives/topic/nutrition-and-weight-status/objectives. Accessed November 6, 2018.

4. Vadiveloo M, Lichtenstein AH, Anderson C, et al. Rapid diet assessment screening tools for cardiovascular disease risk reduction across healthcare settings: a scientific statement from the American heart association. Circ Cardiovasc Qual Outcomes. 2020;13(9):e000094. doi:10.1161/HCQ.0000000000000094

5. Vetter ML, Herring SJ, Sood M, Shah NR, Kalet AL. What do resident physicians know about nutrition? An evaluation of attitudes, self-perceived proficiency and knowledge. J Am Coll Nutr. 2008;27 (2):287-298. doi:10.1080/07315724.2008.10719702

6. Pearson TA, Stone EJ, Grundy SM, et al. Translation of nutritional sciences into medical education: the Nutrition Academic Award Program. Am J Clin Nutr. 2001;74(2):164-170. doi:10.1093/ajcn/ 74.2.164

7. Cresci G, Beidelschies M, Tebo J, Hull A. Educating future physicians in nutritional science and practice: the time is now. $J$ Am Coll Nutr. 2019;38(5):387-394. doi:10.1080/07315724.2018.1551158

8. Daley BJ, Cherry-Bukowiec J, Van Way CW, et al. Current status of nutrition training in graduate medical education from a survey of residency program directors: a formal nutrition education course is necessary. JPEN $J$ Parenter Enteral Nutr. 2016;40(1):95-99. doi:10.1177/0148607115571155

9. Crowley J, Ball L, Hiddink GJ. Nutrition in medical education: a systematic review. Lancet Planet Health. 2019;3(9):e379-e389. doi:10.1016/S2542-5196(19)30171-8

10. Johnston E, Mathews T, Aspry K, Aggarwal M, Gianos E. Strategies to Fill the Gaps in Nutrition Education for Health Professionals through Continuing Medical Education. Curr Atheroscler Rep. 2019;21(4):13. doi:10.1007/s11883-019-0775-9

11. Aspry KE, Van Horn L, Carson JAS, et al. Medical Nutrition Education, Training, and Competencies to Advance Guideline-Based Diet Counseling by Physicians: a Science Advisory From the American Heart Association. Circulation. 2018;137(23):e821-e841. doi:10.1161/CIR.0000000000000563

12. Devries S, Agatston A, Aggarwal M, et al. A deficiency of nutrition education and practice in cardiology. Am J Med. 2017;130 (11):1298-1305. doi:10.1016/j.amjmed.2017.04.043

13. Johnston E, Beasley J, Jay M, Wiedemer J, Etherton PK. Practical nutrition for the primary care provider: a pilot test. Med Sci Educ. 2019;29(2):363-373. doi:10.1007/s40670-019-00700-w 
14. Jay M, Gillespie C, Schlair S, Sherman S, Kalet A. Physicians' use of the 5As in counseling obese patients: is the quality of counseling associated with patients' motivation and intention to lose weight? BMC Health Serv Res. 2010;10:159. doi:10.1186/1472-6963-10-159

15. Johnston EA, Petersen KS, Beasley JM, et al. Relative validity and reliability of a diet risk score (DRS) for clinical practice. $B M J N P H$. 2020:bmjnph-2020-000134. doi:10.1136/bmjnph-2020-000134
16. Beasley JM, Sardina P, Johnston EA, et al. Integrating a diet quality screener into a cardiology practice: assessment of nutrition counseling, cardiometabolic risk factors, and patient/provider satisfaction. Curr Dev Nutrition. 2020;3(1):24

\section{Publish your work in this journal}

Advances in Medical Education and Practice is an international, peerreviewed, open access journal that aims to present and publish research on Medical Education covering medical, dental, nursing and allied health care professional education. The journal covers undergraduate education, postgraduate training and continuing medical education including emerging trends and innovative models linking education, research, and health care services. The manuscript management system is completely online and includes a very quick and fair peer-review system. Visit http://www.dovepress.com/testimonials.php to read real quotes from published authors. 